University of Nebraska - Lincoln

DigitalCommons@University of Nebraska - Lincoln

USDA Wildlife Services - Staff Publications

U.S. Department of Agriculture: Animal and Plant Health Inspection Service

8-9-2019

\title{
Low Secondary Risks for Captive Coyotes from a Sodium Nitrite Toxic Bait for Invasive Wild Pigs
}

\author{
Nathan P. Snow \\ Texas A\&M University-Kingsville \& U.S. Department of Agriculture/Animal and Plant Health Inspection \\ Service/Wildlife Services, National Wildlife Research Center \\ Katherine E. Horak \\ U.S. Department of Agriculture/Animal and Plant Health Inspection Service/Wildlife Services, National \\ Wildlife Research Center \\ Simon T. Humphrys \\ Invasive Animals Cooperative Research Centre \\ Linton D. Staples \\ Animal Control Technologies Australia Pty Ltd \\ David G. Hewitt \\ Follow thisand. additional works at: https:/digitalcommons.unl.edu/icwdm_usdanwrc \\ Part of the Natural Resources and Conservation Commons, Natural Resources Management and \\ Policy Commons, Other Environmental Sciences Commons, Other Veterinary Medicine Commons, \\ See next page for additional authors \\ Population Biology Commons, Terrestrial and Aquatic Ecology Commons, Veterinary Infectious Diseases \\ Commons, Veterinary Microbiology and Immunobiology Commons, Veterinary Preventive Medicine, \\ Epidemiology, and Public Health Commons, and the Zoology Commons
}

Snow, Nathan P.; Horak, Katherine E.; Humphrys, Simon T.; Staples, Linton D.; Hewitt, David G.; and VerCauteren, Kurt C., "Low Secondary Risks for Captive Coyotes from a Sodium Nitrite Toxic Bait for Invasive Wild Pigs" (2019). USDA Wildlife Services - Staff Publications. 2294.

https://digitalcommons.unl.edu/icwdm_usdanwrc/2294

This Article is brought to you for free and open access by the U.S. Department of Agriculture: Animal and Plant Health Inspection Service at DigitalCommons@University of Nebraska - Lincoln. It has been accepted for inclusion in USDA Wildlife Services - Staff Publications by an authorized administrator of DigitalCommons@University of Nebraska - Lincoln. 
Authors

Nathan P. Snow, Katherine E. Horak, Simon T. Humphrys, Linton D. Staples, David G. Hewitt, and Kurt C. VerCauteren 


\title{
Low Secondary Risks for Captive Coyotes from a Sodium Nitrite Toxic Bait for Invasive Wild Pigs
}

\author{
NATHAN P. SNOW, ${ }^{\mathbf{1 , 2}}$ Caesar Kleberg Wildlife Research Institute, Texas AङM University-Kingsville, 700 University Boulevard, MSC 218, \\ Kingsville, TX 78363, USA \\ KATHERINE E. HORAK, U.S. Department of Agriculture/Animal and Plant Health Inspection Service/Wildlife Services, National Wildlife Research \\ Center, 4101 LaPorte Avenue Fort Collins, CO 80521, USA \\ SIMON T. HUMPHRYS, Invasive Animals Cooperative Research Centre, 33 Flemington Street Glenside, South Australia 5062, Australia \\ LINTON D. STAPLES, Animal Control Technologies Australia Pty Ltd, 46-50 Freight Drive, Somerton Victoria 3062, Australia \\ DAVID G. HEWITT, Caesar Kleberg Wildife Research Institute, Texas AEM University-Kingsville, 700 University Boulevard, MSC 218, Kingsville, \\ TX 78363, USA \\ KURT C. VerCAUTEREN, U.S. Department of Agriculture/Animal and Plant Health Inspection Service/Wildlife Services, National Wildlife Research \\ Center, 4101 LaPorte Avenue Fort Collins, CO 80521, USA
}

\begin{abstract}
An acute toxic bait is being developed to deliver micro-encapsulated sodium nitrite (SN) to stimulate severe methemoglobinemia and humane death for invasive wild pigs (Sus scrofa), thereby providing a new tool for reducing their populations. During April 2016, we evaluated sensitivity to SN and outcomes of secondary consumption in the ubiquitous mammalian scavenger, coyote (Canis latrans), to determine secondary risks of consuming carcasses of wild pigs that died from consuming the $\mathrm{SN}$ toxic bait. At the National Wildlife Research Center in Fort Collins, Colorado, USA, we first evaluated whether coyotes fed carcasses of domestic pigs killed by consumption of SN bait showed signs of SN intoxication. Second, we conducted chemical analysis of residual SN in the coyotes for evidence of SN passing from pigs to coyotes. Last, we conducted an acute oral toxicity test $\left(\mathrm{LD}_{50}\right)$ with $\mathrm{SN}$ for coyotes by feeding them meatballs containing capsules of $\mathrm{SN}$. We found no evidence that captive coyotes experienced SN intoxication from consuming on carcasses that had been freshly poisoned with $\mathrm{SN}$, despite consuming $\bar{x}=1.6 \mathrm{~kg}$ of tissues/coyote within 24 hours. None of the captive coyotes consumed digestive tracts or stomach contents from poisoned carcasses, which contained the highest levels of residual SN. Chemical analysis indicated that only $\leq 34.14 \mathrm{mg} / \mathrm{kg}$ of residual SN were passed from the tissues of the pigs into the coyotes, confirming that SN does not bioaccumulate. All coyotes quickly vomited various doses of SN during the $\mathrm{LD}_{50}$ test and fully recovered, suggesting a natural defense against secondary poisoning from $\mathrm{SN}$. Testing with captive coyotes indicates that the risks of secondary poisoning for free-ranging coyotes are likely low, although field-testing should be used to confirm. (C) 2019 The Wildlife Society.
\end{abstract}

KEY WORDS feral swine, nontarget risk, pesticide, Sus scrofa, toxicant, wild boar, wildlife damage management.

The invasive wild pig (hereafter, 'wild pigs' [Sus scrofa], also referred to as feral hogs, feral pigs, feral swine, or wild boars; Keiter et al. 2016) is a damaging invasive species that in recent decades has increased in density and geographical range throughout parts of North America, Australia, South

Received: 19 October 2018; Accepted: 20 March 2019

Published: 9 August 2019

${ }^{1}$ E-mail: Nathan.P.Snow@aphis.usda.gov

${ }^{2}$ Current affiliation: U.S. Department of Agriculture/Animal and Plant Health Inspection Service/Wildlife Services, National Wildlife Research Center, 4101 LaPorte Avenue, Fort Collins, CO 80521, USA
America, Africa, and many island nations (Barrios-Garcia and Ballari 2012, Snow et al. 2017b). Wild pigs cause extensive damage to agricultural and natural landscapes and are expensive to control using conventional methods of trapping or shooting (Pimentel 2007, Anderson et al. 2016). In addition, wild pigs are reservoirs of many important zoonotic and livestock diseases (Hahn et al. 1997, Doran and Laffan 2005). They reduce plant species diversity through rooting behaviors (Hone 2002), depredate sensitive species (Taylor and Hellgren 1997, Fordham et al. 2006, Jolley et al. 2010), destroy habitats for native species (van Riper and Scott 2001), and pose risks to threatened and endangered species (McClure et al. 2018). Consequently, wild pigs are considered one of the worst invasive species on 
Earth (Lowe et al. 2000). Development of new methods and tools for controlling wild pigs, such as a toxic bait, are being developed for use in the United States, Australia, and New Zealand (Cowled et al. 2008, Shapiro et al. 2016, Snow et al. 2017a).

Sodium nitrite (SN) was recently identified as a potential new active ingredient for a toxic bait for wild pigs because it was fast-acting, humane, and posed few secondary poisoning risks because it is not expected to accumulate in tissues of wild pigs or the environment (Cowled et al. 2008, Institute of Medical and Veterinary Science 2010, Lapidge et al. 2012, Shapiro et al. 2016, Snow et al. 2018). As such, a new SN toxic bait was recently registered for use on wild pigs in New Zealand (Shapiro et al. 2016), and is under development in the United States (Snow et al. 2017a) and under evaluation for registered use in Australia (J. Wishart, Animal Control Technologies Australia, personal communication). Specifically, a collaborative research effort among the Wildlife Services National Wildlife Research Center (NWRC; USA) of the U.S. Department of Agriculture, the Texas Parks and Wildlife Department (USA), the Invasive Animal Cooperative Research Center (AU), Animal Control Technologies Australia (ACTA; AU) Pty Ltd, and Connovation PTY Ltd (NZ) has developed HOGGONE ${ }^{\circledR}$ (ACTA, Victoria, AU). HOGGONE ${ }^{\circledR}$ contains $100 \mathrm{mg} / \mathrm{g}$ (10\%) of SN incorporated into an oil-based matrix primarily consisting of peanut paste and milled grains (Snow et al. 2016).

As with most toxic baits, the potential risk for unintentional poisoning of nontarget species via direct or secondary exposure requires evaluation. A recently developed wild pig-specific bait station has successfully excluded the most ubiquitous nontarget species-such as raccoons (Procyon lotor), white-tailed deer (Odocoileus virginianus), coyotes (Canis latrans), wild turkeys (Meleagris gallopavo), and rodents-from accessing a toxic bait inside the bait station, thereby lowering the risks of direct poisoning (Snow et al. 2017; Lavelle et al. 2018a,b). Furthermore, a risk assessment estimated no risks of secondary poisoning for nontarget scavenging species from consuming muscle, liver, or eye tissues from carcasses of wild pigs that had consumed a SN toxic bait (Snow et al. 2018). However, if scavengers consumed large amounts of digestive tract tissues or undigested bait from carcasses of wild pigs in a single feeding event, the scavengers could be at risk from secondary poisoning. Therefore, more evaluation of secondary poisoning was warranted.

Coyotes are among the most common mammalian scavenger species in the United States (DeVault et al. 2003), and among the most likely to consume carcasses of wild pigs. Although coyotes prefer to consume muscle tissue from carcasses (Wade and Browns 1982), Lapidge et al. (2012) suggested that canids were among the most likely of any scavenger species to consume the undigested stomach contents of poisoned wild pigs, possibly putting them at potential risk of secondary exposure to $\mathrm{SN}$ toxic bait. Currently, it is unknown whether coyotes will consume enough digestive tract tissues or undigested bait contents to receive dangerous levels of residual SN from carcasses of poisoned wild pigs. Therefore, it is important to evaluate the amount of consumption and lethality for coyotes from consuming poisoned carcasses of wild pigs and determine the sensitivity of coyotes to $\mathrm{SN}$ in carcasses of wild pigs. There are other common scavenging species in the United States (e.g., turkey vultures [Cathartes aura] and black vultures [Coragyps atratus]) that feed from carcasses of wild pigs, which are not considered in this study but will be the subject of future studies.

Our objectives were to evaluate potential risks for captive coyotes from consuming carcasses of domestic pigs that had just died from consuming a SN toxic bait. First, we fed captive coyotes carcasses of poisoned domestic pigs to determine whether any symptoms of secondary poisoning occurred. Then, we evaluated the sensitivity of those coyotes to $\mathrm{SN}$ by conducting a modified up-and-down acute oral toxicity test $\left(\mathrm{LD}_{50}\right.$; Bruce 1985$)$ using differing concentrations of $\mathrm{SN}$ in ground meat from domestic pigs. Findings from this study will be used to inform the potential risks for free-ranging coyotes from consuming carcasses of wild pigs exposed to an $\mathrm{SN}$ toxic bait.

\section{METHODS}

We conducted all testing during March-May, 2016. We tested coyotes inside open-air research buildings at the U.S. Department of Agriculture, Animal Plant and Health Inspection Service, Wildlife Services, NWRC in Fort Collins, Colorado, USA. Overall, we tested 16 adult (i.e., $2-4$ years old) and intact, captive-reared coyotes ( 8 males and 8 females) that were individually housed in adjacent cages ( 1.8 height $\times 1.2$ width $\times 2.4$ length $\mathrm{m}$ ) with attached den boxes ( 0.5 height $\times 0.6$ diameter $\mathrm{m}$ ). Coyotes were provided $285 \mathrm{~g}$ of Mazuri ${ }^{\circledR}$ Exotic Canine Food (Land O' Lakes, Inc., St. Paul, MN, USA) daily and water ad libitum. Prior to conducting this study, the coyotes had not been exposed to carcasses of prey; therefore, we acclimated the coyotes to consuming tissues from domestic pig carcasses. First, for approximately 1 week we added $\geq 50 \mathrm{~g}$ of ground domestic pork meat to their daily rations. Then, for 2 days we offered one-quarter of a whole domestic piglet (20-25 days old) including viscera. Finally, for 2 days we offered one-half of a whole domestic piglet including viscera. We confirmed that all coyotes readily consumed most or all of the carcasses prior to initiating the study. All components of this study were evaluated and approved by the NWRC's Institutional Animals Care and Use Committee (QA-2568).

\section{Carcass Consumption Test}

For the carcass consumption study, we obtained 20 young domestic pigs weighing an average of $11.3 \mathrm{~kg}(\mathrm{SD}=4.3)$ and randomly separated them into treatment (12) and control (8) groups. Pigs were individually housed in adjacent cages $(0.8$ height $\times 0.6$ width $\times 1.0$ length $\mathrm{m})$ in 2 simulated natural-environment rooms at the NWRC, and maintained on domestic pig food (AGL SHO PIG STR 15 CX; Agfity, Inc., Eaton CO, USA) offered at 7\% of body mass and water ad libitum daily. To acclimate the pigs to consuming 
the $\mathrm{SN}$ toxic bait, we offered them a placebo bait that was identical to the SN toxic bait, except excluding the SN. We offered the placebo bait for 7 days, at $1 \%$ of body mass for each morning prior to offering the maintenance food. By day 7, we observed that each pig consumed $80-100 \%$ of the placebo bait within 90 minutes of offering.

On the morning of day 8, we offered toxic HOGGONE ${ }^{\circledR}$ bait to the treatment group at $1 \%$ of body mass, which was equivalent to $1,000 \mathrm{mg} / \mathrm{kg}$ of $\mathrm{SN}$ and approximately 2.5 times the $\mathrm{LD}_{99}$ for wild pigs (i.e., estimated at $400 \mathrm{mg} / \mathrm{kg}$; Cowled et al. 2008). We also offered $1 \%$ of body mass of placebo bait to the control group. We allowed the pigs to feed freely on the bait. Once the pigs in the treatment group died, we anesthetized the pigs in the control group using isoflurane gas inside an airtight chamber, and then euthanized them using carbon dioxide gas following guidelines of the American Veterinary Medical Association (Leary et al. 2013).

We immediately offered 1 of the 8 treatment or control pig carcasses, respectively, to each of the coyotes in the randomly selected treatment ( 5 males, 3 females) or control ( 3 males, 5 females) groups. The coyotes had been previously fasted for approximately 12 hours prior to being offered a pig carcass. We cut an approximately $10-\mathrm{cm}$ incision along the ventral abdomen of each carcass to provide easy access to the digestive tracts for the coyotes, and simulate feeding of other scavengers that may occur prior to coyotes in the wild (e.g., turkey vultures and black vultures). The remaining 4 treatment pig carcasses were placed in an adjacent, empty cage to provide an average environmental correction for evaporative mass loss when measuring how much of each carcass each coyote consumed.

We allowed coyotes to consume pig carcasses for 24 hours. We monitored each coyote continuously for the first 6 hours using live-feed video cameras to reduce disturbance by observers. We recorded consumption of the pig carcasses (e.g., from front quarter, hind quarter, viscera, or other) and any observable symptoms of SN intoxication, such as incoordination, vomiting, shallow or deep breathing, unresponsiveness, or death (Snow et al. 2018). For the remaining 18 hours, we monitored coyotes via recording video from the cameras.

After 24 hours, we collected and weighed any portions of remaining pig carcasses. We anesthetized treatment coyotes using isoflurane gas inside their closed denbox, and then euthanized them using carbon dioxide gas following guidelines of the American Veterinary Medical Association (Leary et al. 2013). Then, we examined the coyotes for evidence of SN exposure. From each coyote, we immediately sampled their stomachs, stomach contents, small intestine (i.e., $\sim 15-\mathrm{cm}$ section starting from duodenum), liver, and striated muscle (i.e., $\sim 2.5 \mathrm{~cm}^{3}$ from right hind quarter). Simultaneously, we also sampled the stomachs and stomach contents from the 4 treatment pigs that were not fed to coyotes to determine levels of residual SN to which the coyotes were exposed. We also used the levels of residual $\mathrm{SN}$ in the stomach contents of pigs to understand how much of the SN was metabolized or broken down from the bait in the carcasses. We immediately vacuum-sealed and froze all samples until chemical analysis was completed.

Chemical analyses of all samples were performed by Southwest Research Institute (San Antonio, TX, USA) using high-performance anion-exchange chromatography to quantify the concentration of residual nitrite. The method was calibrated using 9 concentration points of nitrite from 0.00001 to $0.002 \%$ nitrite and a blank ( $0 \%)$. The efficiency for recovery from laboratory control samples averaged $92.1 \%$ $(\mathrm{SD}=4.8)$ among sample types, and the method limit of detection was $0.00001 \%$. For all samples, if nitrite was not detected we reported the level to be consistent with the method limit of detection. We converted the concentrations of nitrite $(\mathrm{mg} / \mathrm{kg})$ to $\mathrm{SN}$ using molecular weights to make inferences relative to the active ingredient. We did not analyze the SN levels in the control coyotes because they were used for the second phase of this study described below. Therefore, in the absence of published levels of SN in canids, we made inferences about baseline levels of SN in coyotes using data from wild pigs that served as control animals published in Snow et al. (2018). Baseline levels were all $\leq 30.0 \mathrm{mg} / \mathrm{kg}$ of SN detected in the carcasses of the control animals. We operated under the assumption that baseline levels would be similar between coyotes and wild pigs given that both are omnivore-generalists with overlapping range throughout much of the United States.

For data analysis, we compared the amount of pig carcasses that were consumed between the treatment and control groups of coyotes using a linear model in the base package of Program R (v3.4.1; R Foundation for Statistical Computing, Vienna, Austria). We also used linear models to test whether the amount of SN in the stomach contents of pigs and coyotes was influenced by the amount of SN toxic bait or pig carcasses, respectively, that they consumed. We also compared levels of SN detected among the different tissue and stomach content samples taken from coyotes. For all models, we examined the parameter estimates $(\beta)$ and $95 \%$ confidence intervals (CIs) of the interaction for a lack of overlap of 0 to indicate statistical and biological influences.

\section{Modified Up-and-Down Procedure}

We used the 8 coyotes that were control animals in the consumption test for the $\mathrm{LD}_{50}$ test. We initiated a modified up-and-down procedure following the OECD 425 guidelines for acute oral toxicity (Organisation for Economic Cooperation and Development 2001). Our method was modified from typical up-and-down procedures because we allowed the coyote to consume the SN via free-feeding, rather than using an oral gavage method. However, we ensured that the SN was consumed in a single, rapid dose similar to how delivery would occur from oral gavage.

We dosed the coyotes by concealing micro-encapsulated SN inside clear gelatin capsules (Capsule Depot Inc., Richmond Hill, Ontario, Canada) that rapidly dissolved once consumed. We hid gel capsules inside ground domestic pork meatballs that weighed approximately $40 \mathrm{~g}$ because coyotes could swallow these in a single bite, based 
on observations during the acclimation phase. We monitored consumption of the meatballs to ensure that the coyotes swallowed the entire meatball and gel capsule with SN.

We initiated the up-and-down procedure for the first randomly selected coyote using a dose of $175 \mathrm{mg} / \mathrm{kg}$ of SN. We used this dose, expecting it was slightly under the true $\mathrm{LD}_{50}$ for coyotes based on the reported $\mathrm{LD}_{50}$ for rats of $180 \mathrm{mg} / \mathrm{kg}$ delivered orally (Material Safety Data Sheet, CAS\#: 7632-00-0, http://www.sciencelab.com/msds.php? msdsId =9927272). We randomly selected each subsequent coyote and dosed it with a higher or lower dose of $\mathrm{SN}$, depending on whether the preceding coyote survived or not. If the preceding coyote survived, the subsequent coyote received the next higher dose, and vice versa. For specific doses, we generated a dose progression of 55, 74, $98,131,175,233,310,410$, and $550 \mathrm{mg} / \mathrm{kg}$ based on an estimated slope of the dose-response curve of 8.0 $(\sigma=0.125)$. For comparison, acute oral doses ranging from 60 to $250 \mathrm{mg} / \mathrm{kg}$ were reported lethal for a variety of species (Lapidge and Eason 2010), and therefore were covered by our dose progression. We dosed each coyote only one time, and dosed only one coyote per day. We stopped dosing based on the stopping rules outlined in Organisation for Economic Cooperation and Development (2001), or if the coyotes repeatedly regurgitated the $\mathrm{SN}$ before intoxication occurred. The stopping rules considered were 1) 3 consecutive coyotes survive at the highest dose $(550 \mathrm{mg} / \mathrm{kg})$; 2) 5 reversals occur in any 6 coyotes tested; and 3) $\geq 4$ coyotes followed the first reversal and the likelihood ratios exceeded the critical value (2.5). We dosed a final coyote as a control using $410 \mathrm{mg} / \mathrm{kg}$ of microencapsulated sugar instead of SN inside of the gelatin capsules. We monitored all surviving coyotes for 2 weeks following the dosing procedure to examine for any chronic effects (i.e., lethargy, loss of appetite, or death).

We estimated the $\mathrm{LD}_{50}$ and $95 \%$ CIs using the maximum likelihood method with the acute oral toxicity stat program (AOT425StatPgm; EPA.gov) developed for Test Guideline 425 (Organisation for Economic Cooperation and Development 2001). We also applied linear models to evaluate whether the dose ingested by coyotes influenced the timing of the onset of symptoms and recovery that we observed.

\section{RESULTS}

\section{Carcass Consumption Test}

Average mass of coyotes in the treatment and control groups did not differ $(\beta=-0.81,95 \% \mathrm{CI}=-2.49-0.86)$, and averaged $11.3 \mathrm{~kg}(\mathrm{SE}=0.38)$. Average mass of pig carcasses offered to coyotes did not differ by treatment group $(\beta=3.74,95 \% \mathrm{CI}=-0.17-7.65)$, and averaged $12.4 \mathrm{~kg}(\mathrm{SE}=1.0)$.

Pigs in the treatment group consumed an average proportion of $0.63(\mathrm{SD}=0.17)$ of the $\mathrm{SN}$ toxic bait offered. The control group consumed $0.98(\mathrm{SD}=0.06)$ of the placebo bait offered. Pigs in the treatment group consumed an average of $75.2 \mathrm{~g}(\mathrm{SD}=37.0)$ of $\mathrm{SN}$ toxic bait, equating to an average of $645.5 \mathrm{mg} / \mathrm{kg}$ of $\mathrm{SN}(\mathrm{SD}=163.8)$. All pigs in the treatment group succumbed to the $\mathrm{SN}$ toxic bait. We observed the first symptoms of intoxication (e.g., incoordination) in pigs at an average of 27.7 minutes $(\mathrm{SD}=10.5)$ following offer of the bait, and death an average of 38.1 minutes ( $\mathrm{SD}=15.0$ ) post-offering.

We did not observe any symptoms of SN intoxication or death among coyotes after consuming the carcasses of poisoned pigs. The only potential symptom of SN intoxication that we observed was that one of the treatment coyotes regurgitated approximately 4.25 hours after beginning to consume the pig carcass. However, analysis of the vomitus revealed negligible levels of SN $(9.38 \mathrm{mg} / \mathrm{kg})$ and the coyote had not consumed any of the digestive tract from the pig carcass; therefore, we concluded that the regurgitation event was not related to SN exposure. We found no evidence the amounts of pig carcasses consumed by coyotes differed $(\beta=-0.64,95 \% \mathrm{CI}=-1.64-0.36)$ between the treatment $(\bar{x}=1.6 \mathrm{~kg}, \mathrm{SE}=0.4)$ and control $(\bar{x}=2.2 \mathrm{~kg}, \mathrm{SE}=0.3)$ groups. The average proportion of pig carcasses consumed by coyotes within the 24-hour period was 0.17 ( $\mathrm{SE}=0.02$ ). Two coyotes in the control group consumed portions of the stomach and stomach contents of the pig carcass, however, whereas none of the coyotes in the treatment group did. Most consumption was focused on the upper neck, shoulders, and hind quarters of the pig carcasses.

Chemical analysis of pig carcasses 24 hours after ingesting the toxic bait indicated that the amount of residual SN in the stomach contents of carcasses was related to the amount of $\mathrm{SN}$ consumed $(\beta=1,150.00,95 \% \mathrm{CI}=5.40-2,294.39)$. However, only an average of $8.4 \%(\mathrm{SE}=1.04)$ of the $\mathrm{SN}$ consumed by pigs was detected in the stomach contents of the pig carcasses 24 hours postingestion (Table 1). Stomach contents $(\beta=6.61,95 \% \mathrm{CI}=0.65-12.58$; Table 1$)$ and small intestines $(\beta=11.23,95 \% \mathrm{CI}=5.79-16.68)$ of coyotes had the highest levels of SN detected compared with other tissues sampled. However, we found no evidence that the amount of SN consumed by the pig influenced the amount of $\mathrm{SN}$ detected in the stomach contents of coyotes $(\beta=11.90,95 \% \mathrm{CI}=-0.71-24.51)$.

Table 1. Means $(\mathrm{mg} / \mathrm{kg}$ ) and standard errors (SE) of sodium nitrite (SN) detected in samples from domestic pigs that consumed lethal doses of a $\mathrm{SN}$ toxic bait, and coyotes that consumed carcasses of those domestic pigs at the National Wildlife Research Center (NWRC) Fort Collins, Colorado, USA, during April 2016. All samples were taken 24 hours after initial consumption of the $\mathrm{SN}$ toxic bait by the pigs and offering their carcasses to coyotes.

\begin{tabular}{lrrrrr}
\hline & \multicolumn{2}{c}{ Coyote } & & \multicolumn{2}{c}{ Pig } \\
\cline { 2 - 3 } \cline { 5 - 6 } Sample & \multicolumn{1}{c}{$\bar{x}^{\mathbf{a}}$} & SE & & $\bar{x}^{\mathbf{a}}$ & \multicolumn{1}{c}{ SE } \\
\hline Stomach contents & $34.14 \mathrm{~A}$ & 20.6 & $8,400.00 \mathrm{~A}$ & $1,040.53$ \\
Stomach (without contents) & $3.97 \mathrm{~B}$ & 0.55 & $2,883.75 \mathrm{~B}$ & 697.55 \\
Small intestine & $23.53 \mathrm{~A}$ & 2.64 & & & \\
Liver & $7.94 \mathrm{~B}$ & 1.38 & & \\
Muscle & $1.41 \mathrm{~B}$ & 0.02 & & \\
& & & & &
\end{tabular}

${ }^{a}$ Letters signify statistical differences among the sample types for each species, respectively, at the level of $\alpha=0.05$. 


\section{Modified Up-and-Down Procedure}

On average, coyotes ingested meatballs and $\mathrm{SN}$ within 150 seconds of being offered $(\mathrm{SD}=123.7)$. None of the coyotes tested in the modified up-and-down procedure died; therefore, a $\mathrm{LD}_{50}$ could not be estimated. The resulting sequential doses tested were $175,233,310$, and $410 \mathrm{mg} / \mathrm{kg}$ of SN. All coyotes vomited quickly after ingestion $(\bar{x}=34.3 \mathrm{~min}, \mathrm{SE}=7.2)$, and vomited between 1 and 5 times. The dose ingested did not influence how quickly vomiting occurred $(\beta=-0.13,95 \% \mathrm{CI}=-0.30-0.41)$. Other than vomiting, the only other symptom of SN intoxication observed was a 20-minute period of incoordination for one coyote (dosed at $233 \mathrm{mg} / \mathrm{kg}$ ) that began 90 minutes postingestion. This coyote vomited 3 times (i.e., 50,69 , and 80 minutes postingestion) before showing signs of incoordination, Two of the coyotes partially reconsumed their vomitus (dosed at 310 and $410 \mathrm{mg} / \mathrm{kg}$, respectively), but then vomited again following reconsumption. Recovery of all coyotes happened quickly following the initial vomiting event $(\bar{x}=68.8 \mathrm{~min}, \mathrm{SE}=23.9)$. Recovery time was not influenced by how quickly vomiting occurred $(\beta=1.30$, $95 \% \mathrm{CI}=-8.77-11.37)$ or by the magnitude of the dose ingested $(\beta=-0.02,95 \% \mathrm{CI}=-1.55-1.52)$. The control coyote dosed with sugar did not vomit or show any observable signs of discomfort.

\section{DISCUSSION}

We found little evidence to suggest that captive coyotes were susceptible to secondary poisoning by a $\mathrm{SN}$ toxic bait consumed by feeding on carcasses of poisoned pigs for 24 hours. More than $91 \%$ of the SN consumed by pigs was metabolized or broken down inside the pigs within 24 hours postdeath, even though the pigs consumed $>1.5$ times their lethal dose of SN. Similar results were also reported by Snow et al. (2018) when they measured SN concentrations immediately following the death of wild pigs (i.e., 90\% reduction of the SN consumed), suggesting that the quick metabolism or break-down of $\mathrm{SN}$ in tissues and acidic gastric contents greatly reduces the risks of secondary SN exposure via scavenging of carcasses. Consequently, we observed no signs of intoxication for the captive coyotes from consuming poisoned pig carcasses, despite coyotes consuming approximately $1.6 \mathrm{~kg}$ of the carcasses. This amount of carcass consumption was similar to that observed from captive coyotes with sheep, providing confidence that consumption was typical in this study (Connolly et al. 1976).

A lack of secondary effects on the coyotes is not surprising, considering the captive coyotes consumed mostly muscle tissue from the pig carcasses, not the stomach contents or digestive tracts that contained the highest levels of residual SN. Free-ranging coyotes may be more food stressed, and thus more likely to consume those portions of the carcass. In a worst-case scenario calculation, 1) assuming that freeranging coyotes only consume stomach contents from pig carcasses (containing an average of $8,400 \mathrm{mg} / \mathrm{kg}$ of residual $\mathrm{SN}$; Table 1), 2) assuming that coyotes have an estimated $\mathrm{LD}_{50}$ within the range reported of most-to-least sensitive identified for wild mammals $(58-525 \mathrm{mg} / \mathrm{kg}$; Snow et al. 2018), and 3) assuming that average coyotes weigh $11.3 \mathrm{~kg}$ as in this study: we estimate that coyotes would need to eat 78-706 g of stomach contents to be at risk of secondary poisoning. Pigs in this study were only able to consume an average of $75.2 \mathrm{~g}$ of the SN toxic bait before becoming intoxicated and succumbing to the bait. Therefore, coyotes would likely need to consume stomach contents from $\geq 1$ pig carcass to ingest enough $\mathrm{SN}$ to be at risk. Additionally, coyotes would need to ingest those stomach contents rapidly (i.e., during a single feeding) for the $\mathrm{SN}$ to have an acute lethal effect from methemoglobinemia, otherwise $\mathrm{SN}$ is metabolized without harm (Snow et al. 2018).

Coyotes in the treatment group appeared to select against the digestive tracts and stomach contents from the poisoned carcasses, despite the fact that we provided easy access to these organs with an incision. However, coyotes typically begin feeding on carcasses from the hind quarter or behind the ribs, which is similar to what we observed (Wade and Browns 1982). We likely should have allowed the coyotes more time to consume the carcasses to increase the likelihood of consuming the viscera. Interestingly, 2 of the control coyotes partially consumed the stomachs and stomach contents compared with none of the coyotes offered poisoned carcasses, indicating some possibility that the residual $\mathrm{SN}$ in the digestive tracts of the treatment pigs may have been aversive to coyotes. Snow et al. (2018) speculated that once SN becomes exposed inside of the stomachs of pigs, the contents will acquire an aversive salty taste and strong odor from the SN breakdown (i.e., including the formation of nitric oxide gas). Furthermore, coyotes select for digestive tracts when milk is found in the stomachs, and therefore likely avoid consuming digestive tracts with aversive contents (Wade and Browns 1982). Regardless, digestive organs of domestic sheep were commonly consumed by coyotes in one study, and entire carcasses including the digestive organs were reportedly consumed often by food-stressed coyotes (Connolly et al. 1976, Wade and Browns 1982). Therefore, coyotes in the wild may be more willing to consume digestive tracts and stomach contents from carcasses of poisoned pigs. This is an important line of future research.

Additionally, in the unlikely event that coyotes consumed a dangerous amount of SN from a carcass, our results indicate that the coyotes would vomit to expel the SN rapidly and recover. The vomiting reflex is used by most animals to protect against noxious and potentially harmful conditions, including pharmaceutical toxicity (Borison and Wang 1953). Our observations indicated that the coyotes vomited quickly after release of the SN from the gel capsule and breakdown of the micro-encapsulation coating, within 34 minutes. For comparison, $70 \%$ of wild pigs vomited 120 minutes after consumption of a SN toxic bait, but still succumbed to SN intoxication (Snow et al. 2018). These results suggest that the quicker an animal expels SN the better the chances of recovery, which provides important implications for other scavengers of wild pigs that readily vomit (e.g., turkey vultures; Vogel 1950). Similar to the coyotes in our study, vomiting by coyotes was suspected to reduce lethality from a prototype toxic bait containing 
theobromine and caffeine (Gese et al. 2012). Vomiting has been observed with other canids (i.e., wild dogs [Canis spp.]) from oral exposure to sodium cyanide (Hooke et al. 2006). Vomiting by coyotes was also observed as an aversive response to ingesting lithium chloride, and following ingestion of carcasses of Texas horned lizards (Phrynosoma cornutum) that contain antipredator compounds (Horn 1983, Sherbrooke and Mason 2005). We expect that this response protected coyotes from digesting dangerous doses of $\mathrm{SN}$ in our study, and subsequently from acute methemoglobinemia.

Finally, results for the chemical analyses showed no evidence that coyotes were receiving dangerous levels of SN from consuming poisoned pig carcasses, albeit they did not consume the most toxic portions (i.e., digestive tracts and stomach contents). The highest levels of SN detected in the treatment coyote tissues and stomach contents $(34.14 \mathrm{mg} / \mathrm{kg})$ were equivalent to the levels detected in unexposed wild pigs that served as control animals in a previous study (i.e., $30.0 \mathrm{mg} / \mathrm{kg}$; Snow et al. 2018). These low concentrations are not surprising considering that $\mathrm{SN}$ is not expected to bioaccumulate and dissipates quickly upon consumption (Lapidge et al. 2012).

\section{MANAGEMENT IMPLICATIONS}

Based on results from this captive study, we found little evidence to suggest that free-ranging coyotes are likely to experience secondary poisoning from consuming carcasses of wild pigs poisoned with a SN toxic bait. The captive coyotes did not consume the most toxic portions (i.e., stomach contents and digestive tracts) of the pig carcasses, although free-ranging coyotes might consume those portions. Regardless, those portions did not contain enough SN to adversely affect coyotes upon consumption unless multiple carcasses were scavenged at once. Further, the captive coyotes all vomited and recovered when fed a lethal dose of $\mathrm{SN}$, representing an effective defense against secondary poisoning. Overall, we surmise that the risk of secondary poisoning for free-ranging coyotes is low, although fieldtesting should be used to confirm.

\section{ACKNOWLEDGMENTS}

We thank C. Blass, N. Crider, C. Ellis, J. Farrar, J. Fischer, J. Halseth, M. Lavelle, E. VanNatta, and C. Wickham for assisting with the study. We thank the Animal Care staff at the National Wildlife Research Center for assisting with housing, daily care, and handling of the study animals. We thank B. Hall and T. Larosa from Animal Control Technologies Australia Pty Ltd for producing and shipping test materials. We thank anonymous reviewers for their comments on this manuscript. The research was supported by the U.S. Department of Agriculture. Mention of commercial products or companies does not represent an endorsement by the US government.

The author, Linton D. Staples, owns the company Animal Control Technologies Australia Pty Ltd. All remaining authors declare that they have no conflict of interest.

\section{LITERATURE CITED}

Anderson, A., C. Slootmaker, E. Harper, J. Holderieath, and S. A. Shwiff. 2016. Economic estimates of feral swine damage and control in 11 US states. Crop Protection 89:89-94.

Barrios-Garcia, M. N., and S. A. Ballari. 2012. Impact of wild boar (Sus scrofa) in its introduced and native range: a review. Biological Invasions 14:2283-2300.

Borison, H. L., and S. C. Wang. 1953. Physiology and pharmacology of vomiting. Pharmacological Reviews 5:193-230.

Bruce, R. D. 1985. An up-and-down procedure for acute toxicity testing. Fundamental and Applied Toxicology 5:151-157.

Connolly, G. E., R. M. Timm, W. E. Howard, and W. M. Longhurst. 1976. Sheep killing behavior of captive coyotes. Journal of Wildlife Management 40:400-407.

Cowled, B. D., P. Elsworth, and S. J. Lapidge. 2008. Additional toxins for feral pig (Sus scrofa) control: identifying and testing Achilles' heels. Wildlife Research 35:651-662.

DeVault, T. L., O. E. Rhodes Jr., and J. A. Shivik. 2003. Scavenging by vertebrates: behavioral, ecological, and evolutionary perspectives on an important energy transfer pathway in terrestrial ecosystems. Oikos 102:225-234.

Doran, R. J., and S. W. Laffan. 2005. Simulating the spatial dynamics of foot and mouth disease outbreaks in feral pigs and livestock in Queensland, Australia, using a susceptible-infected-recovered cellular automata model. Preventive Veterinary Medicine 70:133-152.

Fordham, D., A. Georges, B. Corey, and B. W. Brook. 2006. Feral pig predation threatens the indigenous harvest and local persistence of snakenecked turtles in northern Australia. Biological Conservation 133:379-388.

Gese, E. M., P. A. Darrow, J. A. Shivik, B. A. Kimball, J. D. Eisemann, and J. K. Young. 2012. Effectiveness of theobromine and caffeine mixtures in coyote lure operative devices as a predacide: a simulated field study. Sheep \& Goat Research Journal 27:26-31.

Hahn, E., G. Page, P. Hahn, K. Gillis, C. Romero, J. Annelli, and E. Gibbs. 1997. Mechanisms of transmission of Aujeszky's disease virus originating from feral swine in the USA. Veterinary Microbiology 55:123-130.

Hone, J. 2002. Feral pigs in Namadgi National Park, Australia: dynamics, impacts and management. Biological Conservation 105:231-242.

Hooke, A. L., L. Allen, and L. K.-P. Leung. 2006. Clinical signs and duration of cyanide toxicosis delivered by the M-44 ejector in wild dogs. Wildlife Research 33:181-185.

Horn, S. W. 1983. An evaluation of predatory suppression in coyotes using lithium chloride-induced illness. Journal of Wildlife Management 47:999-1009.

Institute of Medical and Veterinary Science. 2010. Assessing the humaneness and efficacy of a new feral pig bait in domestic pigs. Pages 1-11 in Report for the Australian Government Department of the Environment, Water, Heritage and the Arts, Canberra, Australia, http://www.environment.gov.au/system/files/resources/091b0583-f35c-40b3-a530f2e0c307a20c/files/pigs-imvs-report.pdf. Accessed 9 May 2016.

Jolley, D. B., S. S. Ditchkoff, B. D. Sparklin, L. B. Hanson, M. S. Mitchell, and J. B. Grand. 2010. Estimate of herpetofauna depredation by a population of wild pigs. Journal of Mammalogy 91:519-524.

Keiter, D. A., J. J. Mayer, and J. C. Beasley. 2016. What is in a "common" name? A call for consistent terminology for nonnative Sus scrofa. Wildlife Society Bulletin 40:384-387.

Lapidge, S. J., and C. T. Eason. 2010. Pharmacokinetics and methaemoglobin reductase activity as determinants of species susceptibility and non-target risks from sodium nitrite manufactured feral pig baits. Invasive Animals Cooperative Research Centre, Canberra, Australia.

Lapidge, S., J. Wishart, L. Staples, K. Fagerstone, T. Campbell, and J. Eisemann. Development of a feral swine toxic bait $\left(\operatorname{Hog}-G_{0 n}{ }^{\circledR}\right)$ and bait hopper (Hog-Hopper ${ }^{\mathrm{TM}}$ ) in Australia and the USA. 2012. Pages 19-24 in S. N. Frey, editor. Proceedings of the $14^{\text {th }}$ Wildlife Damage Management Conference. U.S. Department of Agriculture Animal and Plant Health Inspection Service. https://www.aphis.usda.gov/ wildlife_damage/nwrc/publications/12pubs/fagerstone121.pdf. Accessed 20 May 2019.

Lavelle, M. J., N. P. Snow, J. M. Halseth, J. C. Kinsey, J. A. Foster, and K. C. VerCauteren. 2018a. Development and evaluation of a bait station for selectively dispensing bait to invasive wild pigs. Wildlife Society Bulletin 42:102-110. 
Lavelle, M. J., N. P. Snow, J. M. Halseth, E. H. VanNatta, H. N. Sanders, and K. C. VerCauteren. 2018b. Evaluation of movement behaviors to inform toxic baiting strategies for invasive wild pigs (Sus scrofa). Pest Management Science 74:2504-2510.

Leary, S., W. Underwood, R. Anthony, S. Cartner, D. Corey, T. Grandin, C. B. Greenacre, S. Gwaltney-Bran, M. A. McCrackin, R. Meyer, D. Miller, J. Shearer, and R. Yanong. 2013. AVMA guidelines for the euthanasia of animals: 2013 edition, American Veterinary Medical Association, Schaumburg, Illinois, USA.

Lowe, S., M. Browne, S. Boudjelas, and M. De Poorter. 2000. 100 of the world's worst invasive alien species: a selection from the global invasive species database. International Union for Conservation of Nature/Species Survival Commission/Invasive Species Specialist Group. Hollands Printing, Auckland, New Zealand.

McClure, M. L., C. L. Burdett, M. L. Farnsworth, S. J. Sweeney, and R. S. Miller. 2018. A globally-distributed alien invasive species poses risks to United States imperiled species. Scientific Reports 8:5331.

Organisation for Economic Cooperation and Development. 2001. OECD guideline for testing of chemicals 425. Acute oral toxicity-up and down procedure. Organisation for Economic Cooperation and Development, https://doi.org/10.1787/9789264071049-en. Accessed 18 Apr 2019.

Pimentel, D. 2007. Environmental and economic costs of vertebrate species invasions into the United States. Pages 2-8 in G. W. Witmer, W. C. Pitt, and K. A. Fagerston, editors. Managing vertebrate invasive species: proceedings of an international symposium. U.S. Department of Agriculture, Animal and Plant Health Inspection Service, Wildlife Services, National Wildlife Research Center, Fort Collins, Colorado, USA.

Shapiro, L., C. Eason, C. Bunt, S. Hix, P. Aylett, and D. MacMorran. 2016. Efficacy of encapsulated sodium nitrite as a new tool for feral pig management. Journal of Pest Science 89:489-495.
Sherbrooke, W. C., and J. R. Mason. 2005. Sensory modality used by coyotes in responding to antipredator compounds in the blood of Texas horned lizards. Southwestern Naturalist 50:216-222.

Snow, N. P., J. A. Foster, J. C. Kinsey, S. T. Humphrys, L. D. Staples, D. G. Hewitt, and K. C. VerCauteren. 2017a. Development of toxic bait to control invasive wild pigs and reduce damage. Wildlife Society Bulletin 41:256-263.

Snow, N. P., J. A. Foster, E. H. VanNatta, K. E. Horak, S. T. Humphrys, L. D. Staples, D. G. Hewitt, and K. C. VerCauteren. 2018. Potential secondary poisoning risks to non-targets from a sodium nitrite toxic bait for invasive wild pigs. Pest Management Science 74:181-188.

Snow, N. P., J. M. Halseth, M. J. Lavelle, T. E. Hanson, C. R. Blass, J. A. Foster, S. T. Humphrys, L. D. Staples, D. G. Hewitt, and K. C. VerCauteren. 2016. Bait preference of free-ranging feral swine for delivery of a novel toxicant. PLoS ONE 11:e0146712.

Snow, N. P., M. A. Jarzyna, and K. C. VerCauteren. 2017b. Interpreting and predicting the spread of invasive wild pigs. Journal of Applied Ecology 54:2022-2032.

Snow, N. P., M. J. Lavelle, J. M. Halseth, C. R. Blass, J. A. Foster, and K. C. VerCauteren. 2017c. Strength testing of raccoons and invasive wild pigs for a species-specific bait station. Wildlife Society Bulletin 41:264-270.

Taylor, R. B., and E. C. Hellgren. 1997. Diet of feral hogs in the western South Texas Plains. Southwestern Naturalist 42:33-39.

van Riper, C., and J. Scott. 2001. Limiting factors affecting Hawaiian native birds. Studies in Avian Biology 22:221-233.

Vogel, H. H. 1950. Observations on social behavior in turkey vultures. The Auk 67:210-216.

Wade, D., and J. Browns. 1982. Procedures for evaluating predation on livestock and wildlife. Publication No. B-1429, Texas Agricultural Extension Service, Texas A\&M University, College Station, USA.

Associate Editor: Gervais. 